\title{
Postgraduate Courses and Training in Paediatrics in BICH
}

1. BICH has course for FCPS in General Paediatrics (2nd part): Student can be registrared twice in a year, in the months of January and July.

2. BICH and Dhaka Shishu (Children) Hospital is a recognized center by BCPS for training in FCPS (Paeditric Medicine and Surgery).

3. It is a recognized centre for course and training in different subspeciality of Paediatrics like Neonatology, Paediatric Nephrology, Paediatric Haematology and Oncology, Paediatric Pulmonology, Paediatric Neuroscience and Paeditric Cardiology.

4. There is MD Residency program in General Paediatrics, Neonatology, Paediatric Nephrology and MS Paediatric Surgery. Phase A commences in the month of March every year. There is also MD Paediatrics and Paediatric Surgery Non Residency Courses which commences in the month of January and July.

5. DCH course: Once in a year in the month of July.

6. Other courses conducted by $\mathrm{BICH}$ are

- Paediatric Nursing.

- BSc in Health Technology.

- Three months certificate course: Every year the institute conducts 3 months certificate course on Paediatrics for general practitioners \& other post graduate candidates e.g. MCPS.

- Training programme on Essential Newborn Care for doctors and nurses, KMC (Kangaroo Mother Care) training, ETAT (Emergency Triage, Assessment and Treatment) training, IMCI (Integrated management of childhood illness), newborn and paediatric standards and use of oxygen therapy for hypoxemia management etc. are conducted by BICH.

\author{
Contact Person : Academic Director \\ Bangladesh Institute of Child Health \\ Sher-e-Bangla Nagar, Dhaka - 1207.
}

Contact : Phone No. 55059063, 55059064, 55059051-60 Ext. 411.

E-mail: infodshjournal@gmail.com, info.bich@gmail.com 